\title{
Ebstein's anomaly of tricuspid valve with rheumatic mitral stenosis: a rare association
}

\author{
Sanjeev Asotra, Rajeev Merwaha, Davinder Pal Singh, Kunal Mahajan
}

Department of Cardiology, Indira Gandhi Medical College, Shimla, Himachal Pradesh, India

\section{Correspondence to} Dr Kunal Mahajan, kunalmahajan442@gmail.com

Accepted 3 March 2016

\section{DESCRIPTION}

A 16-year-old girl presented with progressive exertional dyspnoea and palpitations of 3-year duration. The medical history revealed one episode of fever with migratory polyarthritis at the age of 7 years, but it was not further evaluated. On presentation, she was in sinus rhythm with a pulse rate of $88 / \mathrm{min}$ and blood pressure of $110 / 80 \mathrm{~mm} \mathrm{Hg}$. Examination revealed a tapping apical impulse in the fifth intercostal space, inside the mid-clavicular line, and a grade 3 parasternal heave. Auscultation revealed loud S1 with an opening snap. There was a mid-diastolic rumble at the apex, with presystolic accentuation. A pansystolic murmur of tricuspid regurgitation was audible. Basal crepitations and peripheral oedema were absent. Transthoracic echocardiography revealed severe rheumatic mitral

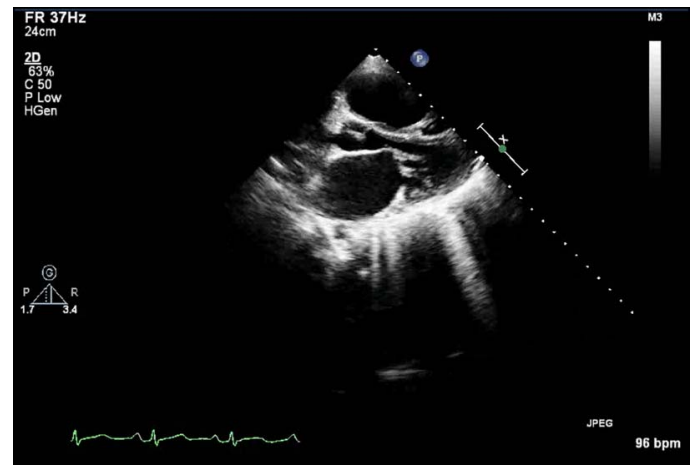

Video 1 Transthoracic echocardiogram, parasternal long-axis view, showing a thick and doming anterior mitral leaflet. The posterior mitral leaflet is also thickened with markedly reduced mobility. Also note the apical displacement of the septal tricuspid leaflet.

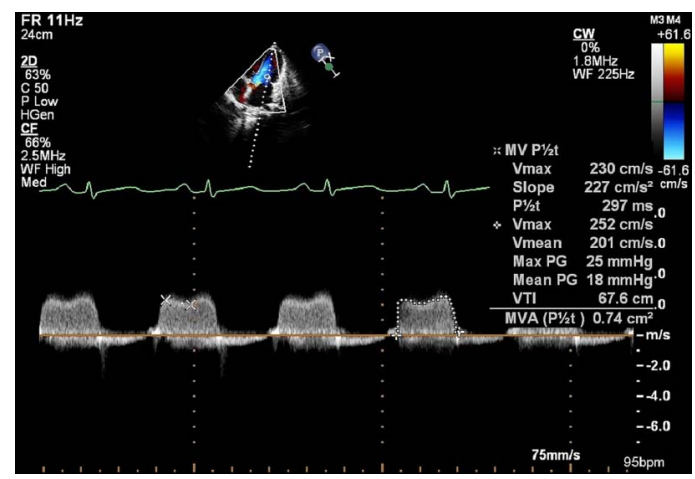

Morwaha R, Singh DP, et al.
Merite: BMJ Case Rep Published online: [please include Day Month Year] doi:10.1136/ bcr-2016-214974

CrossMark
Figure 1 Estimation of gradients across mitral valve (peak gradient $=25 \mathrm{~mm} \mathrm{Hg}$, mean gradient $=18 \mathrm{~mm} \mathrm{Hg}$ ) and calculation of mitral valve area $\left(0.74 \mathrm{~cm}^{2}\right)$ by pressure half time.

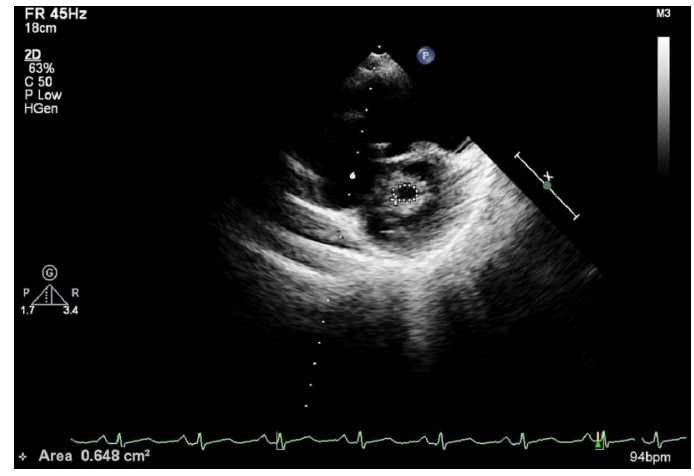

Figure 2 Calculation of mitral valve area $\left(0.64 \mathrm{~cm}^{2}\right)$ by two-dimensional planimetry.

stenosis (MS) (video 1) (peak and mean mitral valve gradient of 25 and $18 \mathrm{~mm} \mathrm{Hg}$, respectively, and mitral valve area (MVA) of $0.74 \mathrm{~cm}^{2}$ by pressure half time (figure 1) and $0.64 \mathrm{~cm}^{2}$ by twodimensional planimetry (figure 2)). In addition, the patient had Ebstein's anomaly of tricuspid valve with apical displacement of septal tricuspid leaflet by $32 \mathrm{~mm}$ and an elongated anterior tricuspid leaflet (figure 3 and video 2). Severe tricuspid regurgitation (video 3) was identified, with a gradient of $58 \mathrm{~mm} \mathrm{Hg}$ (figure 4). The interatrial septum was intact. The patient underwent successful balloon mitral valvotomy (BMV) using the Inoue technique. Post-BMV, MVA increased to $1.5 \mathrm{~cm}^{2}$ and peak and mean mitral valve gradient decreased to 17 and $9 \mathrm{~mm} \mathrm{Hg}$, respectively. The patient showed a dramatic improvement in her symptoms. Ebstein's anomaly was not corrected due to lack of associated right heart failure, cyanosis and

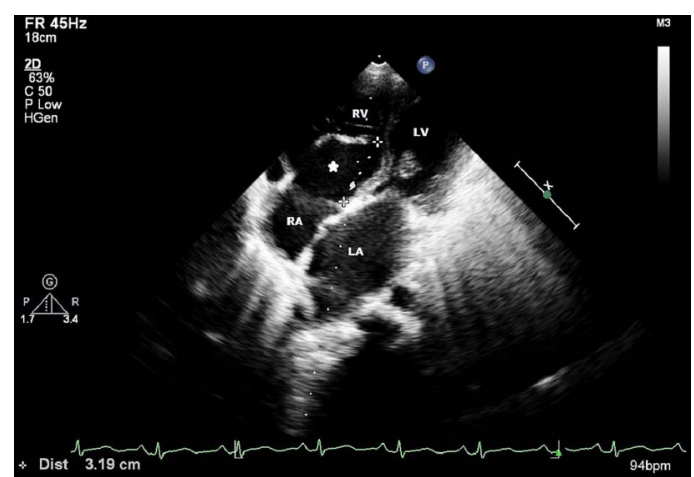

Figure 3 Transthoracic echocardiogram, apical four-chamber view, showing the apical displacement of septal tricuspid leaflet by $31.9 \mathrm{~mm}$. Note the atrialised portion $\left(^{*}\right)$ of the RV. Also note the doming of the anterior mitral leaflet. LA, left artery; LV, left ventricle; $\mathrm{RA}$, right artery; RV, right ventricle. 


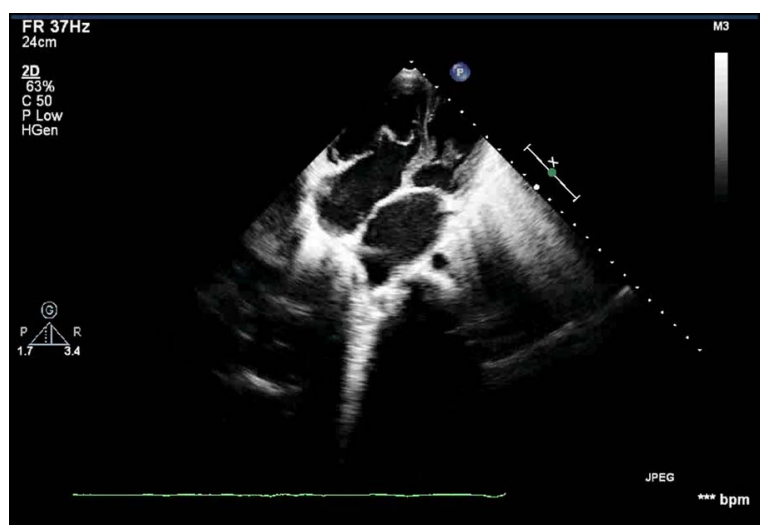

Video 2 Transthoracic echocardiogram, apical four-chamber view, showing the apical displacement of the septal tricuspid leaflet and a sail-like elongated anterior tricuspid leaflet. Thickened mitral valve leaflets with doming of anterior mitral leaflet and fixed posterior mitral valve leaflet are also seen suggestive of rheumatic mitral valve disease.

recurrent paradoxical embolism. Ebstein's anomaly is a rare congenital heart disorder occurring in $\approx 1 / 200000$ live births and accounting for $<1 \%$ of all cases of congenital heart disease. ${ }^{1}$ Acquired rheumatic mitral valve disease is an extremely rare association. Severe MS is likely to alter the natural history of Ebstein's anomaly, leading to a rapid progression of symptoms and an earlier onset of atrial fibrillation, heart failure and pulmonary hypertension. ${ }^{2} \mathrm{BMV}$ in such a complex clinical scenario that offers an excellent outcome. ${ }^{3}$

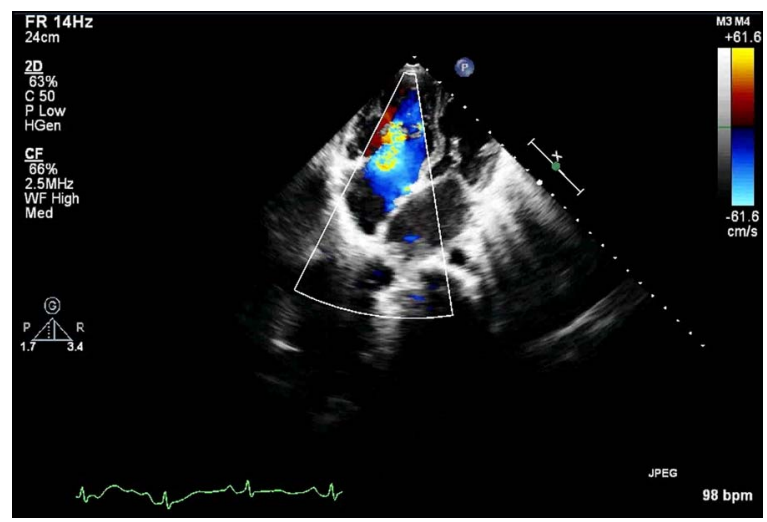

Video 3 Transthoracic echocardiogram, apical four-chamber view, showing eccentric jet of severe tricuspid regurgitation.

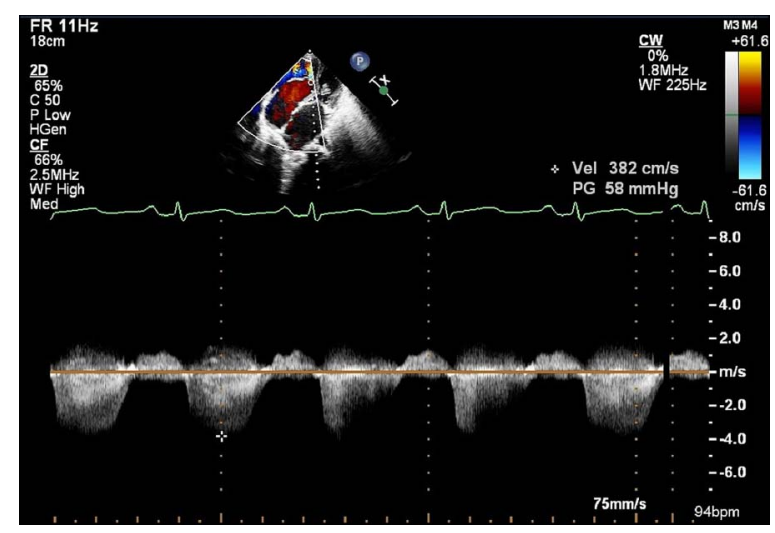

Figure 4 Continuous wave Doppler estimation of gradient across the tricuspid regurgitation jet.

\section{Learning points}

- Ebstein's anomaly of tricuspid valve is a rare anomaly with a reported prevalence of $1 / 200000$ live births.

- Acquired rheumatic mitral stenosis in association with Ebstein's anomaly of tricuspid valve is extremely rare.

- This can lead to earlier onset of adverse complications, which include atrial fibrillation, hypertension and heart failure, in a patient of Ebstein's anomaly.

- Balloon mitral valvotomy offers an excellent treatment approach in the absence of contraindications. Relief of mitral stenosis decreases the pulmonary hypertension and severity of associated tricuspid regurgitation.

Competing interests None declared.

Patient consent Obtained.

Provenance and peer review Not commissioned; externally peer reviewed.

\section{REFERENCES}

1 Attenhofer Jost CH, Connolly HM, Edwards WD, et al. Ebstein's anomaly-review of a multifaceted congenital cardiac condition. Swiss Med Wkly 2005;135:269-81.

2 Jayaprasad N, Thomas V, Madhavan S, et al. A rare association of Ebstein's anomaly of tricuspid valve with rheumatic mitral stenosis. Echocardiography 2007;24:176-8.

3 Tewari S, Kapoor A, Moorthy N. Successful balloon mitral valvotomy in rheumatic mitral stenosis with Ebstein's anomaly. J Heart Valve Dis 2011:20:601-3.

Copyright 2016 BMJ Publishing Group. All rights reserved. For permission to reuse any of this content visit http://group.bmj.com/group/rights-licensing/permissions.

BMJ Case Report Fellows may re-use this article for personal use and teaching without any further permission.

Become a Fellow of BMJ Case Reports today and you can:

- Submit as many cases as you like

- Enjoy fast sympathetic peer review and rapid publication of accepted articles

- Access all the published articles

- Re-use any of the published material for personal use and teaching without further permission

For information on Institutional Fellowships contact consortiasales@bmjgroup.com

Visit casereports.bmj.com for more articles like this and to become a Fellow 